\title{
RELATIONSHIP OF THE METHOD OF OBTAINING THE ORIGINAL BILLET WITH THE ACCURACY OF MANUFACTURING OF THE EXTENDED AXISYMMETRIC BODIES
}

\author{
A. S. Yamnikov ${ }^{1}$, I. A. Matveev ${ }^{2}$, E. N. Rodionova ${ }^{1}$ \\ ${ }^{1}$ Tula State University (Tula, Russia) \\ ${ }^{2}$ NPO "Splav" named after A. N. Ganichev (Tula, Russia)
}

E-mail:yamnikovas@mail.ru; ivan_matveev@list.ru; masik-ele@yandex.ru

\begin{tabular}{|c|c|}
\hline AUTHOR'S INFO & A B STRACT \\
\hline $\begin{array}{l}\text { A. S. Yamnikov, Dr. Eng., } \\
\text { Prof., Dept. of Manufacturing } \\
\text { Technology, } \\
\text { I. A. Matveev, Cand. Eng., } \\
\text { Deputy Head of Production } \\
\text { Dept., } \\
\text { E. N. Rodionova, Engineer, } \\
\text { Post-graduate Student }\end{array}$ & $\begin{array}{l}\text { A comparative description of the technology for producing blanks for the artillery shell cases or the rocket shell bod- } \\
\text { ies using flat rolled stock or rolled tubular products is given. It is noted that the lower cost of flat rolled stock leads to } \\
\text { its wider application for stamping blanks of cartridge caps or bodies, including cutting a circle from flat rolled stock, } \\
\text { convolution and several transitions of drawing, alternating with heat treatment. It is noted that the disadvantage } \\
\text { of this technology are the errors in the shape of the blanks, amounting to } 0.75 \div 1.5 \text { of the tolerance for diametrical } \\
\text { dimensions. When machining, these errors decrease according to the laws of copying the errors, however, the ani- } \\
\text { sotropy of the material of the part blank leads to the appearance of errors in the shape-ovality and curvature of the } \\
\text { pipe, which lead to the formation of a large radial runout of the prefabricated rocket body. It has been found that } \\
\text { the scattering fields of all output quality parameters exceed the existing tolerances: radial runout of the assembled }\end{array}$ \\
\hline $\begin{array}{l}\text { Key words: } \\
\text { initial billet, prefabricated body, } \\
\text { flat rolled stock, hot-deformed } \\
\text { thick-walled pipes, techno- } \\
\text { logical reliability, technological } \\
\text { heredity, radial runout, shape } \\
\text { error, rotary drawing. }\end{array}$ & $\begin{array}{l}\text { body by } 1.3 \text { times; ovality of the middle centering bulge by } 2.15 \text { times. It is shown that the technological process of } \\
\text { manufacturing prefabricated housings using initial blanks from flat rolled stock does not provide the required pre- } \\
\text { cision technology reliability. For the manufacture of monolithic extended axisymmetric bodies, hot-rolled thick- } \\
\text { walled pipes are used as an initial billet. The operations are performed in the following sequence: cutting pipes into } \\
\text { dimensional workpieces; machining (turning, boring); heat treatment (quenching, tempering); machining (fine } \\
\text { turning, boring); rotary drawing (first and second transitions); crimping the thickening; low temperature anneal- } \\
\text { ing. Statistical studies have found a regression equation showing at a confidence level } \beta=0.95 \text {, dependence of the } \\
\text { diameter of the base hole of the workpiece after drawing in from the current value of the diameter before drawing. }\end{array}$ \\
\hline
\end{tabular}

\section{Introduction}

Rocket shell bodies and artillery shell cases have a similar design: thin long cylindrical walls and bulges or bottom at the ends. With the classical technology for the manufacture of blanks for shall cases or bodies, including cutting a circle from flat rolled stock of an anisotropic material of steel 10GN (TU 14-1-1356-75), convolution and several transitions of the drawing, alternating with heat treatment. The choice of this technology is due to the versatility of the technology in comparison with the use of pipe billets, besides, the wholesale price of flat rolled stock or hot-rolled strip is 1.5-2 times lower than that of thick-walled hot-rolled pipe [1].

The disadvantage of this technology are the errors in the shape of the blanks, amounting to $0,75-1.5$ of the tolerance for diametrical dimensions [2-9]. When machining by cutting, these errors decrease according to the laws of copying the errors $[2,3,10]$, however, the anisotropy of the material of the original workpiece leads to the appearance of errors in the shape-ovality and curvature of the pipe.

In most cases, a body with a length of more than $1500 \mathrm{~mm}$ with the wall thickness of 1.5 to $5 \mathrm{~mm}$ is difficult to manufacture in one piece, therefore it is made of several pipes of shorter length. In this case, the geomet- ric errors of the body increase, since the connection of parts is impossible without mutual misalignment of the axes. There are two main requirements for prefabricated housings:

- straightness of the product (small axis bending) required for long products consisting of two or more pipes;

- tightness during storage and operation of the product.

These requirements are provided by the design of the product and the accuracy of its manufacture. Such a prefabricated body (Fig. 1) is obtained by screwing long pipes with a length to diameter ratio $L / D$ from 10 to 30 . The main functional requirement for prefabricated bodies is their free connection with a pipe of a given diameter and curvature,

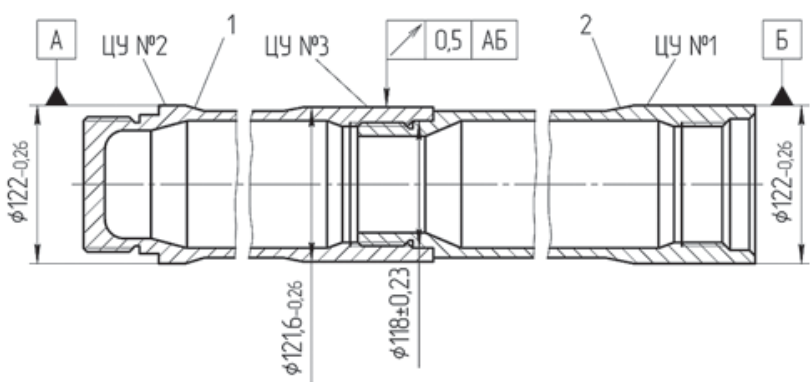

Fig. 1. Prefabricated rocket body with threaded pipe connection 1 and 2 
assessed by the value of the radial runout $\Delta p$ prefabricated body, which is standardized by the drawing $\left(\Delta_{p} \leq 0,5 \mathrm{MM}\right)$, as well as the tightness of the connection, determined in this case by the accuracy of the mutual position of the attachment ends of the pipes after tightening, the normalized value of the one-sided end gap $Z \leq 0.1 \mathrm{~mm}$.

Another parameter regulated in the technical conditions is the deviation of the shape of the threaded and adjacent surfaces in the form of deviations from roundness $[2,3,10]$, which is very significant for the thinwalled parts with a wall thickness from 1.5 to $3 \mathrm{~mm}$ (by $1.2-1.5$ times the diameter tolerance). However, when assembling thin-walled rings and pipes, the shape deviations are somewhat straightened. This is known to the designers, therefore they normalize the average diameter of a smooth cylindrical surface and allow for the ovality of pipes, a larger tolerance of the average diameter. For example, for a $121.6 \mathrm{~mm}$ thickening on pipe 2 (see Fig. 1), the dimensional tolerance is $T_{D}=0.26 \mathrm{~mm}$, and shape tolerance (ovality) $T_{\Delta_{\mathrm{oB}}}=0.3 \mathrm{~mm}$.

Often, parts have overestimated radial and end runout of the mating surfaces, as well as the ovality of the base surfaces. The fact that the manufacture of pipes according to a single technological process on the same machines and with constant adjustment leads to their different quality indicates the presence of hidden technological hereditary ties. The radial runout of the prefabricated body sometimes reaches $\Delta_{p}=1.2-1.5 \mathrm{~mm}$ (with preset value $0,5 \mathrm{~mm}$ ), and the number of the defective assemblies averages from 20 to $30 \%$.

\section{Aim of Research}

Comparative analysis of the influence of technological heredity of body blanks, stamped from a sheet and obtained by rotary drawing from a hot-rolled pipe, on the final accuracy of the bodies.

\section{Obtained Results}

The authors investigated the mechanism of the formation of the output characteristics of the assembled bodies, taking into account the parameters of the pipes manufactured using classical technologies [2, 3]. It was found that the polar distribution of all output quality parameters exceeds the available tolerances: the radial runout of the For all that, only the pipes are used, which have been tested by the plant Quality Control (QC) department making use of the measuring instruments and limit gauges.

Measurements of the actual errors in the manufacture of the base surfaces of the pipes showed that their scattering fields exceed their tolerance fields: the runout of the pipe mating ends by 1.5 times; ovality of threads by 1.33 times, ovality of bands by 1.62 times. In addition, the radial runout of the flanges relative to the thread axes is 2.46 times; runout of ends of complex threaded calibers by 2.58 times; ovality of the outer base surfaces by 1.848 times. Thus, the technological process of manufacturing prefabricated bod-

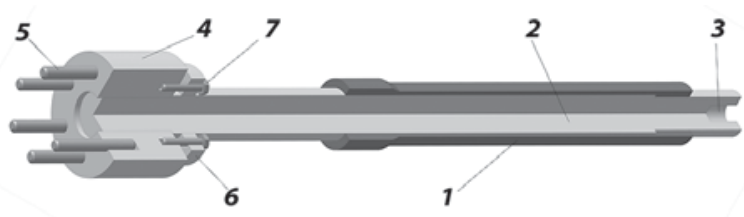

Fig. 2. Basing the workpiece during a rotary drawing: 1-pipe; 2-mandrel; 3 - centering hole; 4-base; 5- pin; 6 - clamping ring; 7 - bolt

ies when using initial blanks from flat rolled stock does not provide the required reliability [2].

For the manufacture of monolithic extended axisymmetric bodies, hot-rolled thick-walled pipes $110 \times 14 \mathrm{~mm}$ in size (according to TU 1308-005-33116077-2001) from structural complex-alloyed steel 12H3GNMFBA (according to TU 1308-001-49967239-98) are used as an initial billet. The operations are performed in the following sequence [11, 12]: cutting pipes into dimensional workpieces; machining (turning, boring); heat treatment (quenching, tempering); machining (fine turning, boring); rotary drawing (first and second transitions); crimping the thickening; low temperature annealing. Analysis of the technology of manufacturing extended axisymmetric bodies, taking into account earlier studies in the field of rotary drawing [13-16], allowed us to assume that the inner base diameter of the workpiece has a great influence on their accuracy characteristics. In a rotary drawing, the workpiece is positioned with a base hole on a mandrel fixed in the machine chuck and pressed by the center.

Tube 1 (Fig. 2) is based on inner base diameter on mandrel 2 .

On the one hand, the pipe is pressed by the rear rotating center entering the centering hole 3 , on the other hand it is installed in the base 4 , which is fixed with six pins 5 directly in the machine spindle. If it is necessary to eliminate the runout, the mandrel is set through the clamping ring 6 by selectively tightening eight bolts 7 , depending on the dial gauge readings. On both transitions, the workpiece hole $\varnothing 116^{+0,35} \mathrm{~mm}$ serves as a double guide base and determines the accuracy of the relative position of the system of machined surfaces relative to the untreated ones (Fig. 3)

The developers of the technology for the manufacture of extended axisymmetric bodies using a rotary drawing, state that depending on the deformation modes, the diameter of the base hole can both decrease and increase [11-16]. Since during rotary drawing the deformation zone moves from one end of the workpiece to the other along a helical line during its rotation, it can be assumed that the rotary drawing is a bifurcation point of the technological process, in which there is no influence of previous operations on the dimensions and properties of the workpiece. For the statistical analysis, a batch of 96 blanks was processed and the actual deviations of the base hole diameter from the nominal value before and after rotary drawing were measured using an internal dial gage with scale factor of $0,01 \mathrm{~mm}$ (Table). The range of the diameter 

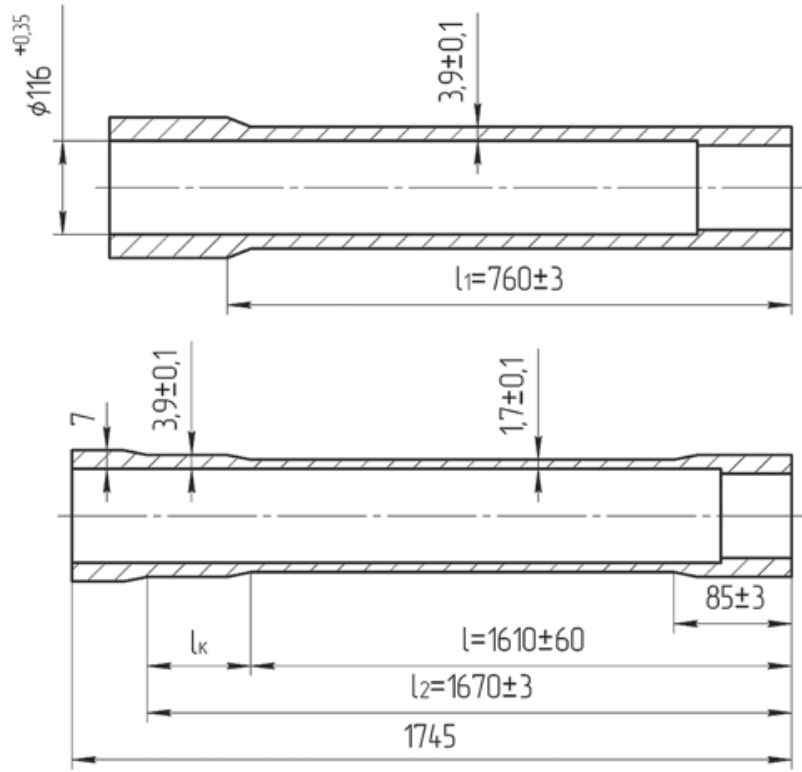

Fig. 3. Sketches of the pipe on the first ( $a$ ) and second (b) transitions of the rotary drawing

of the base hole of the workpiece before the rotary drawing was $x=116.19-116.31 \mathrm{~mm}$ (average value $0,12 \mathrm{~mm}$ ), and after the rotary drawing $y=116.10-116.24 \mathrm{~mm}$ (average value $0,14 \mathrm{~mm}$ ).

For convenience of the data processing, the intervals were taken to be $-C_{x}=C_{y}=0,02 \mathrm{~mm}$. The intervals and the frequency of hitting them with blanks with the dimensions of the base diameter, equal to the ratio of the number of blanks with runout to the number of the measured blanks, are given in the Table, where $x$ and $y$ - the diameter of the base hole before and after drawing, and $\bar{x}$ and $\bar{y}_{x}$ - respectively, their average values (given in brackets).

In works $[16,17]$, it was found that the diameters of the base hole of the workpiece before $\left(x=116.15^{+0,15} \mathrm{~mm}\right)$

\begin{tabular}{|c|c|c|c|c|c|c|}
\hline \multicolumn{7}{|c|}{$\begin{array}{l}\text { The frequency of hitting the diameters of } w \\
\text { with a runout in a given interval }\end{array}$} \\
\hline \multicolumn{7}{|c|}{ Base hole diameter intervals of the workpiece } \\
\hline \multirow[b]{2}{*}{ After rotary drawing $y\left(\bar{y}_{x}\right)$} & \multicolumn{6}{|c|}{ Before rotary drawing $x(\bar{x})$} \\
\hline & 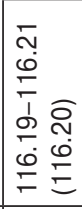 & 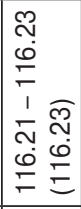 & 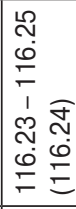 & 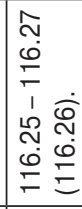 & 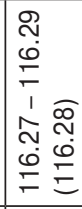 & 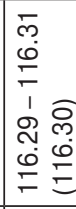 \\
\hline $116.10-116.12(116.11)$ & - & 2 & 6 & 3 & - & - \\
\hline $116.12-116.14(116.13)$ & 1 & 5 & 4 & 2 & 1 & - \\
\hline $116.14-116.16(116.15)$ & 3 & 3 & 6 & 6 & 2 & 2 \\
\hline $116.16-116.18(116.17)$ & - & - & 2 & 9 & - & - \\
\hline $116.18-116.20(116.19)$ & 1 & 3 & 2 & 8 & 5 & 2 \\
\hline $116.20-116.22(116.21)$ & - & 2 & 3 & 5 & 4 & 3 \\
\hline $116.22-116.24(116.23)$ & - & - & - & - & - & 1 \\
\hline$\sum_{i=1}^{l} n_{x_{i}}=96$ & 5 & 15 & 23 & 33 & 12 & 8 \\
\hline
\end{tabular}

and after $\left(y=116^{+0,35} \mathrm{~mm}\right)$ the drawing obey the normal distribution law; statistical characteristics are also determined. Showing a linear relationship between $x$ and $y$, which can be written as a straight line equation. To proceed to the new variables $x$ 'and $y$ 'the formulas were used:

$$
\begin{aligned}
& x^{\prime}=\frac{x-a_{x}}{C_{x}} ; \\
& y^{\prime}=\frac{y-a_{y}}{C_{y}},
\end{aligned}
$$

where $a_{x}$ and $a_{y}$ - new points of reference (in our case, this is the nominal diameter of the base hole: $a_{x}=a_{y}=116 \mathrm{~mm}$ ).

The correlation coefficient, which establishes the strength (tightness) of the correlation relationship with the linear dependence of the variables $x_{i}$ and $y$, was determined by the formula:

$$
r_{x y}=\frac{C_{x y}}{S_{x} S_{y}}=\frac{0,0003}{0,025 \cdot 0,033}=0,364,
$$

where $C_{x y}$ - covariance value of random variables $x$ and $y$; $S_{x}$ and $S_{y}$ - selective variance of the diameter of the base hole of the workpiece, respectively, before and after drawing (statistical characteristics [18]).

Correlation of the dependent variable $y$ of the independent variable $x_{i}$ :

$$
\eta_{y}=\frac{S_{\bar{y}_{x}}}{S_{y^{\prime}}}=\frac{0,716}{1.663}=0,431,
$$

where $S_{\bar{y}_{x}}$ - variance of group means (variance of theoretical values of the effective trait, reflects the influence of factor $x$ on the variation $y$ ); $S_{y^{\prime}}-$ total variance; $\bar{x}$, $\bar{y}_{x}$ - average values of the diameter of the base hole of the workpiece before and after drawing in the considered interval.

The regression equation was obtained in the form:

$$
\tilde{y}_{x}=0,48 x+60.37,
$$

where $\tilde{y}_{x}$ - statistically expected value of the diameter of the base hole of the workpiece after drawing depending on the current value $\mathrm{x}$ of the diameter before drawing.

Fig. 4 shows a graphical interpretation of the experiment check. On the correlation field, the number of points in each cell corresponds to the value of the frequencies indicated in the Table. In Fig. 4, points are also plotted corresponding to the average values $\bar{y}_{x}$ of the base hole of the workpiece after drawing in the interval under consideration, connecting them with segments, we obtain an empirical regression line according to equation (1), i.e., the theoretical regression line.

To assess the adequacy of this model, it is necessary to know the total and inter-interval variance. The variance $\tilde{y}_{x}$ was determined by the formula:

$$
S_{\tilde{y}_{x}}^{2}=\frac{\sum n_{x_{i}}\left(\tilde{y}_{x_{i}}-\bar{y}_{x}\right)^{2}}{\sum n_{x}}=\frac{1399367.731}{96}=14576.747 \mathrm{~mm}^{2} .
$$

Fisher's criterion came up to: 


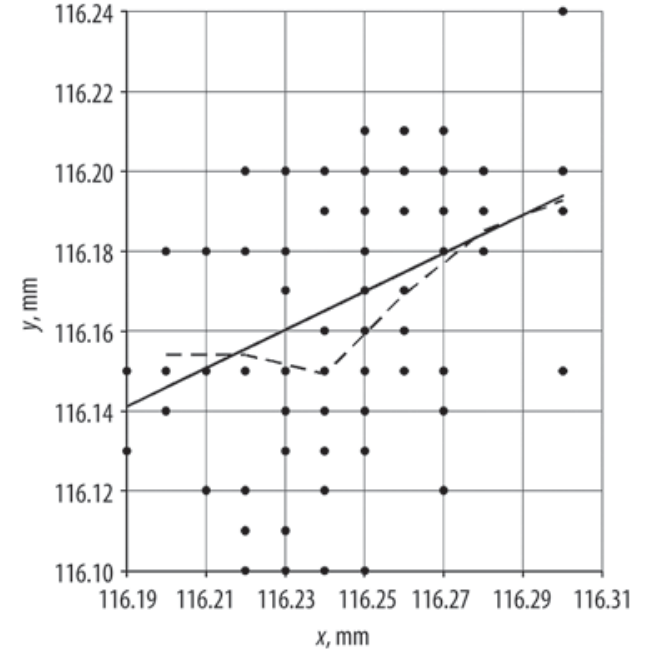

Fig. 4. Graphic interpretation of experimental results:

- - data array; — and - - - - theoretical and empirical regression lines, respectively; $x-$ diameter of the base hole of the workpiece before drawing; $y$-diameter of the base hole of the workpiece after drawing, $\tilde{y}_{x}$ - statistically expected value of the diameter of the base hole of the workpiece after drawing

$$
F=\frac{S_{y}^{2}}{S_{\bar{y}_{x}}^{2}}=\frac{5060.873}{14576.747}=0,347 .
$$

Based on the results of the calculations carried out, the number of degrees of freedom was determined $f-1=6$ (where $f$ - number of intervals), confidential probability $\beta=0.95$ and the tabular value of Fisher's criterion $F_{\mathrm{T}}=3.7$. Since the calculated value $F=0,347<F_{\mathrm{T}}=3.7$, then the resulting model was accepted as an adequate one, i.e., using the regression equation, it is possible to predict the value of $y$ depending on the change in the value of $x$ with the required accuracy, i.e., at $\beta=0.95$.

\section{Conclusion}

1. Manufacturing of prefabricated housings using initial blanks made of flat rolled stock does not provide the required reliability.

2. Manufacturing of monolithic bodies using original blanks from a hot-rolled pipe provides a large margin for the accuracy of the dimensions and shape of the part.

3. Rotary drawing does not completely eliminate the influence of errors of the previous operations on the dimensions and properties of the workpiece. Therefore, the errors of the base diameter of the workpiece are copied on the body with a refinement factor of 0,48 , corresponding to the coefficient in the regression equation.

4. The research results have shown that, if necessary, the accuracy of the bodies can be increased by reducing the limiting tolerance for the base diameter of the workpiece for a rotary drawing. The ratio of the hole diameter tolerance to its scattering field is 1.786 , which guaranteedly exceeds the value of 1.2 required by the criteria of technological reliability, recommended by A. A. Matalin.

\section{REFERENCES}

1. ChermetProkat. Metal supply throughout Russia. Tula [Electronic resource]. URL: https://tula.chermetprokat.ru/. (date of the application 03.07.2020)

2. Yamnikov A. S., Matveev I. A., Rodionova E. N. Manifestation of technological heredity when turning of non-rigid tubular billets. Chernye metally. 2019. No. 5. pp. 36-40.

3. Vasiliev A. S., Yamnikov A. S., Yamnikova O. A., Matveev I. A. Influence of hereditary technological errors of production of a basic pipe on parameters of the assembled propulsion section. Chernye metally. 2019. No. 1. pp. 67-71.

4. Tregubov V. I., Larin S. N., Pasynkov A. A., Nuzhdin G. A. Assessment of the influence of the geometry of the tool on the power parameters of the combined process of drawing and flanging. $\mathrm{Za}$ gotovitelnye proizvodstva v mashinostroenii. 2019. Vol. 17. No. 4. pp. $165-167$.

5. Madureira L. R., Melo F. Q. Deformation of thin straight pipes under concentrated forces or prescribed edge displacements. $\mathrm{Me}$ chanics Research Communications. 2015. Vol. 70. pp. 79-84.

6. Shinkin V. N. Springback coefficient of the main pipelines' steel large diameter pipes under elastoplastic bending. CIS Iron and Steel Review. 2017. Vol. 14, pp. 28-33.

7. Shinkin V. N. Mathematical model of technological parameters' calculation of flanging press and the formation criterion of corrugation defect of steel sheet's edge. CIS Iron and Steel Review. 2017. Vol. 13. pp. 44-47.

8. Kugultinov S. P., Khisamutdinov R. M., Khisarmtdinov M. R. Tool Creation and Operation System Development for Large Engineering Enterprises. World Applied Sciences Journ. 2014. No. 30(5). pp. 588-591.

9. Yakovlev S. S., Tregubov V. I., Osipova E. V. Limiting Deformation in Rotary Drawing of Anisotropic Pipe Blanks with Wall Thinning. Russian Engineering Research. 2016. Vol. 36. No. 6. pp. 472-475.

10. Dalskiy A. M. Hereditary relations of procurement and mechanical assembly industries. Vestnik mashinostroeniya. 1998. No. 1. pp. 34-36.

11. Tregubov V. I., Yakovlev S. S., Osipova E. V. and Belov A. E. Innovative technological processes of rotary drawing of complex-profile axisymmetric parts. Kuznechno-shtampovochnoe proizvodstvo. Obrabotka materialov davleniem. 2013. No. 11. pp. 9-16.

12. Yakovlev S. S., Tregubov V. I., Pilipenko O. V., Remnev K. S. Rotary drawing of axisymmetric shells from anisotropic materials with division of deformation zone. Vestnik mashinostroeniya. 2015. No. 1. pp. 73-78.

13. Kryvyi P. D.; Dzyura V. O.; Tymoshenko N. M.; Krypa V. V. Technological heredity and accuracy of the cross-section shapes of the hydro-cylinder cylindrical surfaces. Proceedings of the ASME 2014 International Manufacturing Science and Engineering Conference Collocated with the JSME 2014 International Conference on Materials and Processing and the 42nd North American Manufacturing Research Conference, Detroit, MI, USA, 9-13 June 2014; p. 2, Paper No. MSEC2014-3946.

14. Duan C. Z., Dou T., Wang M. Research on Influence of Material Hardness and Cutting Conditions on Serrated Chip Formation Process during High Speed Machining of AISI 1045 Hardened Steel. Computer Engineering and Technology (ICCET), AMAE Int. J. on Production and Industrial Engineering, June 2011, Vol. 02, No. 01, 2nd, pp. 321-324.

15. Kishawy H. A., Hosseini A., Moetakef-Imani B., Astakhov V. P. An Energy Based Analysis of Broaching Operation: Cutting Forces and Resultant Surface Integrity. CIRP Annals - Manufacturing Technology. 2012. Vol. 61. Issue 1. pp. 107-110.

16. Yakovlev S. S., Remnev K. S., Tregubov V. I., Pilipenko O. V. Rotary Drawing of Axisymmetric Shells with Distribution of the Deformation Zone. Russian Engineering Research. 2015. Vol. 35. No. 4. pp. 270-276.

17. Tregubov V. I., Larin S. N., Pilipenko O. V., Chernyaev A. V. An approach to improving the quality of cylindrical products obtained by rotary drawing with wall thinning and separation of the deformation zone. Zagotovitelnye proizvodstva v mashinostroenii. 2017. Vol. 15. No. 1. pp. 21-27.

18. Gromyko G. L. The theory of statistics. M.: Infra-M, 2001. 160 p. 